\title{
Corporate Reputation and Firm Performance: An Empirical Analysis of Motor Vehicle Assemblers in Nairobi City County, Kenya
}

\author{
Dennis Mungai Muthoni, Godfrey Muigai Kinyua
}

School of Business, Kenyatta University, Nairobi, Kenya

Email address:

mungaidenno@yahoo.com (D. M. Muthoni),jefkinyua@gmail.com (G. M. Kinyua)

\section{To cite this article:}

Dennis Mungai Muthoni, Godfrey Muigai Kinyua. Corporate Reputation and Firm Performance: An Empirical Analysis of Motor Vehicle Assemblers in Nairobi City County, Kenya. Journal of Business and Economic Development. Vol. 5, No. 2, 2020, pp. $73-81$.

doi: 10.11648/j.jbed.20200502.13

Received: October 26, 2019; Accepted: March 11, 2020; Published: April 10, 2020

\begin{abstract}
The manufacturing sector accounts for approximately sixteen percent of Gross Domestic Product and fourteen percent of employment globally, but its relative size in an economy varies with the stage of development. In Kenya, a strong manufacturing base is considered the foundation upon which long-lasting economic frameworks can be made. The automotive industry is one of the most competitive industries in the manufacturing sector in Kenya today with significant contribution to the Gross Domestic Product. However, data from the Kenya Motor Industry Association has shown that performance of motor vehicles assemblers is on a decline as indicated by the fall in volume of sales reported annually. This study sought to investigate the effect corporate reputation on performance of motor vehicle assemblers. The research variables in this study are underpinned on the resource-based view of the firm. The investigation was guided by descriptive research design. The study targeted a population comprising of employees of motor vehicle assemblers and sought to make field observations on a sample of management employees that was randomly selected using proportionate stratified sampling. Primary data for the investigation was collected using a structured questionnaire. Validity of the questionnaire was assessed and confirmed using opinion from experts and review of relevant literature. A pilot study was carried out using fifteen employees to support the test of reliability of the questionnaire. Descriptive statistics was analyzed using frequencies, percentages, mean, standard deviation and coefficient of variation. Similarly, inferential statistics was analyzed using simple linear regression analysis. The found out that corporate reputation was found to have a statistically significant effect on performance. Practices that promote fairness, equality, diversity and dignity in the workplace should be strengthened at all level of the firms in order to project a good image in the market place.
\end{abstract}

Keywords: Strategic Assets, Corporate Reputation, Firm Performance

\section{Introduction}

Globally, there has been an appreciation and realization that competitive manufacturing is the lifeline of economies as a result of the crucial role it plays in a country's long-term prosperity. A report by Mckinsey Global Institute (MGI) identified performance of the manufacturing sector as a critical component in the economies of both advanced and developing countries [25]. The manufacturing sector is associated with creation of skilled jobs and generation of revenues for national treasuries in form of earning from exports and investment. The sector has a strong beneficial role through its contribution to development of physical infrastructure of a nation that has spill-over effects to other areas such as science, construction and logistics. Indeed, the manufacturing sector has a contribution of approximately sixteen percent to the global Gross Domestic Product (GDP) and fourteen percent of employment.

Notably, Africa is significantly under-industrialized as compared to the other economies of the world [5]. Generally, it is becoming increasingly difficult to industrialize as the level of peak manufacturing employment has been observed to decline with each wave of industrialization from around thirty percent of employment with the first wave of 
smokestack industries three centuries ago to roughly half that today [4]. Moreover, it was noted that for different income groups in a country, the contribution of manufacturing to GDP in Africa has stagnated or contracted since the mid1980s [5]. In addition, the size of the manufacturing sector in Africa has been observed to range from five percent in South Sudan to and forty percent in Swaziland. Notwithstanding the recent trough in the commodity cycle, growth rates amongst African countries since 2000 have been impressive and in some cases, very spectacular. It is, however, a striking fact that the growth of manufacturing sector has not kept pace. The level of industrialization in the African continent has remained low and the contribution of manufacturing sector to growth of GDP has declined [3].

In Kenya, a strong manufacturing base is considered the foundation upon which long-lasting economic framework can initiated and sustained. In its report on manufacturing priority agenda for 2018, the Kenya Association of Manufacturers (KAM) pointed out that the industrial growth in Kenya has stagnated with a GDP contribution of ten percent over the last ten years, and a further reported decline to approximately nine percent in 2016 [15]. Empirical literature is replete with evidence that demonstrates that the manufacturing sector has the largest employment multiplier effect relative to other sectors of the economy. For instance, empirical analysis has indicated that 100 jobs in the manufacturing sector supported 291 jobs in other sectors of the economy [2]. It is the goal of the Kenyan Government to increase the contribution of the manufacturing sector to gross domestic product from the current nine percent to fifteen percent by the year 2022 [15].

According to Kenya National Bureau of Statistics (KNBS), the manufacturing sector in Kenya grew from 3.2\% to 3.5\% in 2014 and 2015 respectively, contributing $10.3 \%$ to gross domestic product [17]. However, the manufacturing sector has on average been shown to grow at a slower rate than the economy, which expanded by $5.6 \%$ in 2015 . This implied that the share of manufacturing in Gross Domestic product (GDP) has been decreasing over time. In addition, KNBS notes that the manufacturing sector recorded an employment growth rate of $13.7 \%$ in 2016 up from $11.9 \%$ in 2015 . The automotive industry has been considered as one of the most competitive industries in the manufacturing sector in Kenya today accounting for $6 \%$ of the gross contribution of the manufacturing sector to Gross Domestic Product [27]. Indeed, the contribution of the automotive industry in Kenya is ranked fifth in Africa in vehicle market, after South Africa, Algeria, Egypt and Morocco [18].

In an ever-changing business environment and globalized economy, the concept of performance is associated with development of firms' resources such as skills, knowledge, ability and experience [6]. Organizational performance is viewed as the ability of a business enterprise to fulfill its mission through sound management, strong governance and a persistent dedication to achieving specific goals over a given period of time [31]. Moreover, performance of a firm comprises achievement of financial and non-financial outcomes that confers an organization the ability to remain viable and sustainable in both the short and long run [8]. Organizational performance may also be noted as the capacity of a firm to effectively accomplish its goals and efficiently make use available physical and human resources [14].

Different researchers have used different measures of performance in their empirical studies. For instance, such measures as return on asset, return on investment, market share, customer satisfaction, employees' satisfaction, competitive position and success rate in launching new product have been used as indicators of firm performance [9]. Likewise, profitability and sales turn-over have also been utilized to assess organizational performance in the case of second-hand motor vehicles firms [22]. Moreover researchers have analyzed performance of automotive industry on the basis of productivity, quality, profitability, customer service, efficiency, market share, and employee satisfaction to assess how performance of motor vehicle assemblers is affected by operation strategy $[24,28]$. This assortment of measures confirms that both traditional and conventional measures can be used to measure performance of a firm in a given industry.

A theoretical prescription has been provided for measurement of performance in terms of four perspectives that broadly embraces a more balanced orientation encompassing both financial and non-financial measures of organization performance. The category of performance measure emphasized by the balanced scorecard includes financial, customer, internal business processes, and learning and growth. However, Kaplan and Norton in an effort to provide a rationale for the inclusion of non-financial measures of performance argue that financial measures by themselves do not provide incentives for success but merely focus on historical data that may not have any relevance to the current and future performance especially in respect to creation of value. The view that in the cases where financial measures are used, present and future operating conditions of a firm are ignored have been supported by [16]. Therefore, non-financial measures comprising of customer retention, turn-around time, lead time, defect rate, employee retention was used to analyze performance of motor vehicle assemblers in this study.

\section{Literature Review}

\subsection{Theoretical Literature Review}

Edith Penrose is considered as the theorist behind the development of the resource-based view of the firm which was however later articulated by other scholars [1, 30, 32]. Resource-based view takes an 'inside-out' view or firmspecific perspective on why some organizations succeed whereas others fail in the market place. According to RBV, firm's abilities aid in creation and addition of value in the customer value chain, developing new innovative products or expanding in new marketplace. The RBV draws upon the resources and capabilities that reside within a given firm so as to build and develop sustainable competitive advantage 
[23]. However, not all the resources of firm are strategic so as to be a source of competitive advantage. The focus of RBV is firm's characteristics and attributes as opposed to the position taken by the industrial organization model that strategy drives acquisition and control of resources and that the external environment is the primary determinant of strategy.

It has been observed that resources of an organization that are valuable, rare, inimitable and non-substitutable enable business enterprises to build and maintain competitive advantage, and consequently realize superior performance in the market place $[1,11,32]$. The RBV holds the proposition that different firms in an industry possess and control a distinct bundle of strategic asset and emphasizes the importance of building a valuable set of resources and combining such resources in unique and dynamic ways to attain corporate success. Barney pointed out that resources are valuable when they aid a firm in the conception of or implementation strategies that increase its efficiency and effectiveness.

$\mathrm{RBV}$ of the firm considers the attributes that are related to past firm's experiences, culture and competences as crucial for the enhanced performance and success. A firm is viewed as a stock of tangible and intangible resources such as physical, financial, social or human, technological, brand names, reputation of the company, employees' knowledge, and intellectual property that facilitate creation of value for customers [13]. Intangible resources such as corporate reputation are path dependent with a socially complex dimension, making them difficult to imitate and as such are a source sustainable competitive advantage.

Competitive advantage is an imperative for enhance corporate performance relative to the competition and is gained through identification, acquisition and control of a stock of key resources [1, 13]. Intangible resources such as culture, human capital, corporate reputation and information technology are viewed as strategic resources because they are valuable, rare, inimitable and non-substitutable and hence can confer an organization with ability to outperform other players in the market place. Even in the case where physical resources such as land, plant, buildings, inventory, equipment and money may be viewed as the genesis of above average returns, the value of such resources has been found to depreciate over time and players in a given industry can easily be acquire them in the factor market ultimately eroding competitive advantage. The RBV is therefore used to provide the theoretical underpinning to corporate reputation and firm performance as the independent and dependent variables respectively in this study.

\subsection{Empirical Literature Review}

An empirical assessment was carried out on the impact of firm reputation on performance using financial indicators [12]. Sample mean and standard deviations were used to generate summary measures of the data observed from both the United State of America and Japan. Inferential statistics involved the use of regression and bivariate correlation analysis. Corporate reputation was found to be positively correlated with both accounting and market-based measures of performance. Hall and Lee determined that favorable reputation is associated with enhanced levels of profitability and performance. The use of traditional financial measures of performance that reflect on past performance of the firms involved inherently weakens the study and particularly given that current and future performance is best informed through non-financial indicators of performance. There is also a contextual difference that makes it impossible to apply the findings of the study under review in the problem identified in the current investigation.

A study conducted on corporate reputation and performance gathered empirical data from 191 private and stated owned enterprises in 16 provinces in China using the questionnaire method [21]. Corporate reputation was measured through brand image, social responsibility, innovation capacity and staff quality. Inferential statistics were analyzed using Spearman correlation coefficients. The results of this research showed that corporate reputation has significant positive relationship with enterprise growth. This positive relationship was confirmed through all pathways tested implying that brand image, social responsibility, innovation capability and staff quality are all important for enterprise growth. The current study is being carried out in Kenya and involves firms in the manufacturing sector.

An investigated carried out on effect of corporate reputation and financial performance of companies listed in the Nairobi Stock Exchange adopted a relational research design with an object of explaining whether there was a relationship among the various research variables [29]. The researcher made use of agreeableness, enterprise, competence and ruthlessness as measures of corporate reputation. Descriptive statistics such as mean scores and standard deviations were used to provide summary measures of the sample. Corporate reputation was found to positively influence performance. Representativeness of the sample is not guaranteed by the technique used in selecting the sample. On the basis of review of theoretical and extant empirical literature the researcher hypothesized the relationship presented in Figure 1.

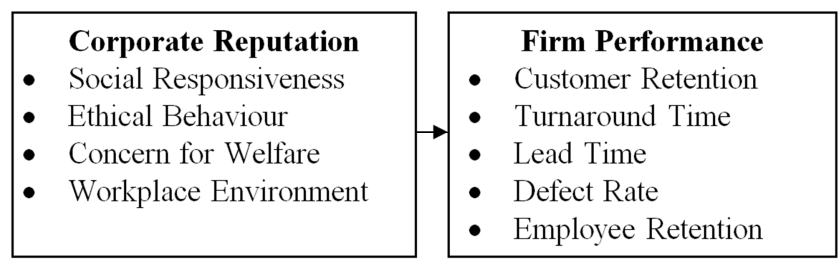

Source: Author and Literature Review (2018).

Figure 1. Conceptual Framework.

The null and alternative research hypotheses for this study were as follows;

$H_{o}$ : Corporate reputation has no effect on performance of motor vehicle assemblers in Nairobi City County, Kenya

$H_{a}$ : Corporate reputation affects performance of motor vehicle assemblers in Nairobi City County, Kenya 


\section{Research Methodology}

The researcher utilized cross-sectional descriptive research design in executing the research strategy. Descriptive research design is concerned with practices, conditions, structures, relationships or differences that exist, opinions held and processes that are going on or trends that are evident. On the other hand, cross-sectional approach for data collection is important for measuring the relationship of variables at a specified point in time with an object of optimizing variations in conditions [19]. It has been argued that descriptive research design is appropriate for surveys as it helps to deepen the understanding of the present state of an entity with respect to the research variables of interest. The research design chosen is appropriate as the study is quantitative in nature and observation was carried out at only point in time in order to enhance uniformity of the environmental context of the research.

The target population of this study constituted of management employees from the eight motor vehicle assemblers in Nairobi City County. These firms include Associated Vehicle Assemblers Ltd., Kenya Vehicle Manufacturers, Toyota East Africa, General Motors East Africa, DT Dobie, General Motors East Africa, Cooper Motors Corporation and Simba Colt Motors.

Table 1. Distribution of Target Population.

\begin{tabular}{lll}
\hline Strata & Target Population & Percentage \\
\hline Senior Level Management & 48 & 15 \\
Middle Level Management & 104 & 32 \\
Functional Level Management & 176 & 53 \\
Total & 328 & 100 \\
\hline
\end{tabular}

Source: Human Resource Departments (2017).

The total population involved 328 management employees distributed non-uniformly in the three layers of management. These employees were selected for the purpose of this study given that they are directly involved in the practices that relates to the four dimensions of strategic assets at the core of this investigation. The results in Table 1 reveal that top management in the eight companies comprises the smallest proportion of the population at $15 \%$. However, functional level managers have the greatest contribution to the population of the study at $53 \%$.

The researcher used proportionate stratified sampling to randomly select a representative sample from the target population. Proportionate stratified random sampling is suitable in situations where the population of interest is heterogeneous on the basis of size as opposed to other attributes [7, 19, 20]. The sample size was determined and attained using Yamane formula [33] as presented in model (1).

$$
\mathrm{n}=\mathrm{N}\left\{1+\mathrm{N}(\mathrm{e})^{2}\right\}^{-1}
$$

Where $\mathrm{n}$ is the sample size, $\mathrm{N}$ is the population size, and $\mathrm{e}$ is the level of precision. At $95 \%$ level of confidence, the level of precision $\mathrm{e}=0.05$, therefore $\mathrm{n}$ is determined thus;

$$
\begin{gathered}
\mathrm{n}=328\left\{1+328(0.05)^{2}\right\}^{-1} \\
=328\{1+0.82\}^{-1} \\
=328\{1.82\}^{-1} \\
=180
\end{gathered}
$$

The sampling proportion that determined the distribution of the sample in the three strata was determined thus;

$$
\mathrm{P}=\mathrm{n} / \mathrm{N}=180 / 328=0.55
$$

Table 2. Distribution of Sample.

\begin{tabular}{lllll}
\hline Strata & $\mathbf{N}_{\mathbf{i}}$ & $\mathbf{p}$ & $\mathbf{n}_{\mathbf{i}}=\mathbf{P} * \mathbf{N}_{\mathbf{i}}$ & Percentage \\
\hline Senior Level Management & 48 & 0.55 & 27 & 15 \\
Middle Level Management & 104 & 0.55 & 57 & 32 \\
$\begin{array}{l}\text { Functional Level } \\
\text { Management }\end{array}$ & 176 & 0.55 & 96 & 53 \\
Total & 328 & & 180 & 100 \\
\hline
\end{tabular}

Source: Researcher (2018).

The results presented in Table 2 show that a sample of 180 respondents was selected from the three strata of management layers. The most dominant contribution to the sample was drawn from the functional level of management where 96 employees making 53\% of the total was observed. Conversely, top management cadre had the least contribution to the sample at $15 \%$.

Primary data was obtained using a structured questionnaire. The researcher used a 5 point Likert Scale that made available five alternative responses for each item in the questionnaire. The use of closed-ended questions allowed the researcher to collect structured responses that supported the use of quantitative data analysis and making sound generalizations. The questionnaire had sections for both general and specific information. General information sought to generate insights into the biographical characteristics of respondents. However, the section of specific information sought to gathering relevant data on the specific objective of the study. The section of specific information was organized into two sub-sections and therefore included questions on corporate reputation and performance.

The researcher solicited opinion and advises of the experts comprising of the faculty in the Department of Business Administration and School of Business in order to ensure that the data collection instrument has face validity. Relevant theoretical and empirical literature was reviewed so as to adequately confirm that the questionnaire has both content and construct validity. The feedback from expert consultation and insights from review of literature formed a good basis for the revision and enhancement of the research instrument.

A pilot study was carried out on fifteen employees of the motor vehicle assemblers with a view to test the reliability of the questionnaire. This was considered necessary for determining internal consistency of the research instrument and therefore aid in assessing the extent to which different set of items in the questionnaire were indeed able to measure the 
various research construct. Reliability of a questionnaire is indicated when the set of measures for the same concept or the same measurements repeated over time produce the same results [10]. The analytical results of the test of reliability are presented in Table 3.

Table 3. Analysis of Test of Reliability.

\begin{tabular}{llll}
\hline Research Variable & $\begin{array}{l}\text { Cronbach's } \\
\text { Alpha Index }\end{array}$ & $\begin{array}{l}\text { Number of } \\
\text { Items }\end{array}$ & Decision \\
\hline Corporate Reputation & 0.739 & 6 & Reliable \\
Firm Performance & 0.783 & 5 & Reliable \\
Aggregate Reliability Score & 0.761 & 11 & Reliable \\
\hline
\end{tabular}

Source: Survey Data (2018).

The researcher used Cronbach's Alpha index to assess the internal consistency and determines if the set of items within the scale actually measures the same construct. Analysis of the results in Table 3 showed that values of Cronbach's Alpha index for corporate reputation and firm performance were 0.7239 and 0.783 respectively. Similarly, the aggregate score of the test of reliability for the two research variables was 0.761 which was well within recommended minimum value of 0.7 for indicating of acceptable level of internal consistency for a questionnaire [10].

The researcher used the letter of research authorization from Kenyatta University to process the permit for conducting the research from National Council of Science, Technology and Innovation (NACOSTI). The research permit was consequently used in seeking consent from management and target respondents, and placing appointments in the respective motor vehicle assembling firms. The transmission of the self-administered questionnaire was executed through the method of drop-andpick later. The researcher established contact persons in the different firms involved in the study to facilitate successful follow-up and thus enhance the response rate. The duly completed questionnaires were later picked from the respondents at the time that had been agreed upon. The researcher developed and maintained a register of questionnaire to help in tracking the movement of the data collection tool.

Research data collected from the field was edited to remove errors and identify any problems in the responses provided. The responses filled in were checked for completeness and consistency. Each questionnaire was assigned a distinct code to minimize errors during data entry and processing, as well as ensure confidentiality. Consequently, data was carefully keyed in to the computer as guided by the assigned codes and a final check was undertaken to confirm accuracy, consistency and completeness. The quantitative data that had been keyed in was analyzed using descriptive and inferential statistics. The researcher used percentages, frequencies, mean, standard deviation and coefficient of variation for analysis of the characteristics of the observed cases.

Inferential statistics involved the use simple linear regression analysis that was intent on establishing the effect of corporate reputation on firm performance as illustrated in Model (2).

$$
\mathrm{Y}=\beta_{0}+\beta_{1} \mathrm{X}_{1}+\varepsilon
$$

Where: $Y=$ Performance

$\mathrm{X}_{1}=$ Corporate Reputation

$\mathrm{B}_{0}, \beta 1=$ Beta coefficients

$\boldsymbol{\varepsilon}=$ error term

Simple regression analysis was performed using the Statistical Package for Social Sciences (SPSS). The results of analysis of inferential statistics were tested for statistical significance using 95\% confidence level as the threshold. Consequently, any resultant $\mathrm{p}$ value that was greater than 0.05 confirmed that there was no relationship between the research variables at $95 \%$ level of confidence. Results of descriptive and inferential analysis were displayed in form of tables and figures.

\section{Research Findings and Discussion}

The researcher administered 180 questionnaires to the sample that had been selected to represent the population of the study. In this case, 132 questionnaires that had been duly filled in were received back from the field. The results of response and non-response are presented in Figure 2.

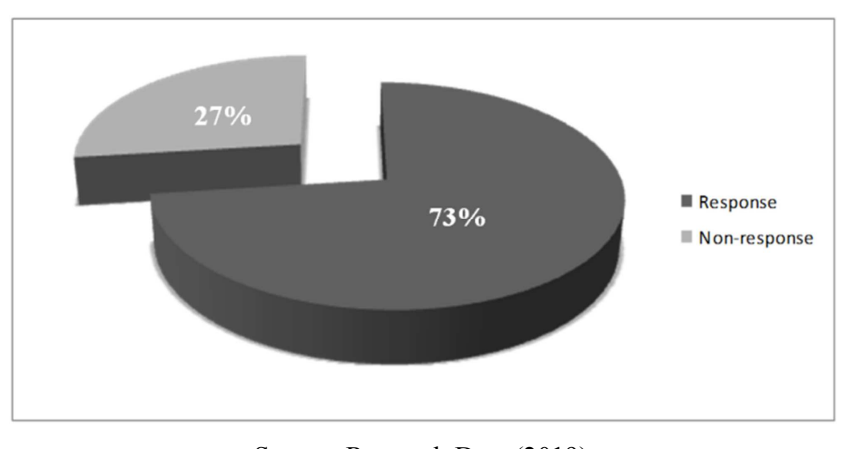

Source: Research Data (2019).

Figure 2. Response and Non-response Rate.

Figure 2 shows that the proportion of completed questionnaires for the purpose of the analysis was seventy three percent. Conversely, twenty seven percent of the questionnaires were not collected from the respondents. This proportion of response rate is acceptable for facilitating generalization of results to the population as it exceed the fifty percent threshold proposed by [26].

\subsection{Descriptive Statistics}

The research made use of mean, standard deviation and coefficient of variation as the summary measures meant to enhance insights into the characteristics of the sample. Sample characteristics were analyzed using responses that had been collected from the respondents as guided by the two research variables. The results of descriptive analysis formed sound basis for performing further statistical analysis that aided making of inferences regarding the population. 
The researcher performed the analysis on the responses of each of the 132 respondents to the six items that had been adopted for measuring corporate reputation. This analysis yielded sample mean, sample standard deviation and coefficient of variation in respect of corporate reputation. The results of descriptive analysis are displayed in Table 4.

Table 4. Descriptive Statistics for Corporate Reputation.

\begin{tabular}{lllll}
\hline Statements on Corporate Reputation & n & Mean & Std. Deviation & Coefficient of Variation \\
\hline Concern for stakeholders' welfare & 132 & 4.00 & .68 & 17 \\
Stakeholders concerns are prioritized & 132 & 4.22 & .85 & .70 \\
Market needs inform the objectives and operations & 132 & 3.94 & .90 & 18 \\
Respect for moral principles & 132 & 4.15 & .93 & .68 \\
There are concerns for stakeholders safety & 132 & 132 & 0.79 & 16 \\
The work environment is friendly & & 4.32 & 4.07 & 19 \\
Aggregate Score & & 132 & .78 \\
\hline
\end{tabular}

Source: Research Data (2019).

Table 4 reveals that the variability of responses observed from statements on corporate reputation varied between $16 \%$ and $25 \%$. Notably, the values of coefficient of variation signify narrow variability demonstrating that individual responses to the different aspects of corporate reputation measured in the motor vehicle assembling firms were clustered around the sample mean of responses. This level of variability is crucial in underscoring the stability of reported sample mean and signifying the possibility of making reliable estimation of population characteristics.

As has been observed from the results, the sample means of the responses ranged between a low of 3.78 and a high of 4.32. This set of sample mean for different items approximates to a value of 4 on the rating scale used in the investigation. The implication of these values is that there was agreement amongst respondent that there was significant level of practice of activities used to measure corporate reputation in motor vehicle assembling firms. These typical responses is further validated by the aggregate values of sample mean, sample standard deviation and sample coefficient of variation of $4.07,0.79$ and $19 \%$. It can therefore be noted that the respondents were in agreement that activities signifying corporate reputation are not practiced but are indeed crucial in the operations of motor vehicle assemblers.

Furthermore, the researcher carried out analysis of sample measures of the responses to the statement on firm performance of motor vehicle assemblers. This analysis generated sample means and sample standard deviations for individual and aggregate responses as shown in Table 5

Table 5. Analysis of Performance Motor Vehicle Assemblers.

\begin{tabular}{lllll}
\hline Statements on Performance & n & Mean & Std. Deviation & Coefficient of Variation \\
\hline Period between order placement and delivery & 132 & 3.97 & .86 & 22 \\
Speed of response to customers issues & 132 & 3.92 & .67 & .68 \\
Reduction of the time taken to offer services & 132 & 3.76 & .76 & 17 \\
Repeat purchases & 132 & 4.08 & .61 & 19 \\
Realization of non-defective output & 132 & 3.84 & 0.71 \\
Aggregate Score & & 3.91 & 16 \\
\hline
\end{tabular}

Source: Research Data (2019).

The results in Table 5 show the analysis of responses to statement regarding performance of motor vehicle assembling firms. The sample mean for the five items that comprised the indicators for performance varied between a low of 3.84 to a high of 4.08. On the other hand, the variability of these responses is generally narrow as demonstrated the sample coefficient of variability values ranging between $16 \%$ and $22 \%$.

The implication of the resulting values of sample mean and variability is that there was agreement amongst respondents that strategic assets of motor vehicle assemblers were well capable of producing outcomes indicated by the items that were used to measure performance in this study. The aggregate scores of sample mean, sample standard deviation and sample coefficient of variation for outcomes of motor vehicle assemblers represented by $3.91,0.71$ and $18 \%$ respectively provide the necessary basis for carrying out further statistical analysis necessary for making conclusion on the link between strategic assets and performance in line with the objective of this study.

\subsection{Test of Hypothesis}

The research conducted simple linear regression analysis with an intention of establishing the statistical equation that can therefore be used to predict or determine the effect of corporate reputation on performance of motor vehicle assemblers operating in Nairobi City County, Kenya. This was realised by regressing corporate reputation on firm performance. The results of the regression analysis are displayed in Tables 6, 7 and 8 respectively. 
Table 6. Output of Model Summary.

\begin{tabular}{llllll}
\hline Model & R & R Square & Adjusted R Square & Std. Error of the Estimate & Durbin-Watson \\
\hline 1 & $.738^{\mathrm{a}}$ & .545 & .484 & .26254 & 2.105 \\
\hline
\end{tabular}

a. Dependent Variable: Firm Performance.

b. Predictors: (Constant), Corporate Reputation.

Source: Research Data (2019).

The outputs of the model summary displayed in Table 6 shows that strategic assets and performance have a strong positive linear relationship as implied by the R-value of 0.738. Equally, the table shows the values of $\mathrm{R}$ square and adjusted R square as 0.545 and 0.484 respectively. Therefore, it follows that the adjusted coefficient of multiple determination which provides the explanatory power of the statistical model established is 0.484 . This has the implication that corporate reputation explains $48.4 \%$ of performance of motor vehicle assemblers in Nairobi City County, Kenya.

Analysis of variance (ANOVA) sought to provide a statistical test for the model fitness. The outputs of this test are presented in Table 7 .

Table 7. Results of Analysis of Variance.

\begin{tabular}{lllllll}
\hline Model & & Sum of Squares & Df & Mean Square & F & Sig. \\
\hline \multirow{2}{*}{1} & Regression & 1.478 & 4 & .370 & 5.361 & $.001^{\mathrm{b}}$ \\
& Residual & 3.102 & 127 & .069 & & \\
& Total & 4.580 & 131 & & & \\
\hline
\end{tabular}

a. Dependent Variable: Firm Performance.

b. Predictors: (Constant), Corporate Reputation.

Source: Field Data (2018).

The results in Table 7 reveal that the established statistical model had a good fit for the observed set of data with a value of F-statistic as 5.361 at a level of significance of 0.001 which is lower than the 0.05 threshold adopted for making conclusion at $95 \%$ level of confidence. These statistical results confirmed that the explanatory power of corporate reputation on firm performance was purely a random occurrence.

The outputs of the regression coefficients of corporate reputation are presented in Table 8.

Table 8. Results of Regression Coefficients.

\begin{tabular}{|c|c|c|c|c|c|c|c|}
\hline & & Unstandardized Coefficients & Standardized Coefficients & $\mathbf{t}$ & Sig. & $95 \% \mathrm{C}$ & \\
\hline & Beta & Std. Error & Beta & & & LB & UB \\
\hline (Constant) & 4.017 & .877 & & 4.583 & .000 & 2.251 & 5.782 \\
\hline $\begin{array}{l}\text { Corporate } \\
\text { Reputation }\end{array}$ & .515 & 147 & .607 & 1.465 & .013 & 1.081 & 2.241 \\
\hline
\end{tabular}

a. Dependent Variable: Firm Performance.

b. Predictor: (Constant), Corporate Reputation.

Source: Research Data (2019).

The results displayed in Table 8 provided the beta values for establishing the statistical mode below.

$$
\text { Performance }=4.017+0.515 \text { Corporate Reputation }
$$

The results of regression coefficients show that holding corporate reputation at a constant zero, performance of motor vehicle assemblers would be at 4.017 . Given that this beta coefficient has $\mathrm{t}=4.583$ and $\mathrm{p}=.000$, it follows that value of the $y$-intercept is statistically significant lending credence to the fact that other factors other than corporate reputation indeed also explain variation of performance of motor vehicle assemblers in Nairobi City County.

The researcher also intended to determine the effect of corporate reputation on performance of motor vehicle assemblers in Nairobi City County, Kenya. The output of regression analysis revealed that corporate reputation has $\beta=0.515 ; t=1.465$ and $p=0.013$. In this case, the value of $t$ lies within the limits of confidence interval established for hypothesis testing implying that the beta coefficient for corporate reputation has a statistically significant effect on performance. The implication of these results is that at $95 \%$ level of confidence, corporate reputation positively affects performance of motor vehicle assemblers. It's therefore important to note that an increase of one unit in the set of activities used to measure corporate reputation in this study is responsible for increasing performance by 0.515 . The researcher therefore concludes that corporate reputation has a positive effect on performance of motor vehicle assemblers in Nairobi City County, Kenya.

These findings corroborate the conclusions of previous studies that corporate reputation has a positive influence on performance $[12,21,29]$. The findings of the study also supported by propositions of resource based view of the firm that intangible resources such as reputation of a firm that are developed through a socially complex process that is path dependent have VRIO characteristics and therefore can be a source of superior performance [11,32]. Indeed, it has been pointed out that intangible resources such as 
reputation are valuable as they enable a firm to conceive of or implement strategies that improve its efficiency and effectiveness [1].

\section{Conclusion and Policy Implication}

The researcher intended to find out the effect of corporate reputation on performance. Corporate reputation was measured using indicators such as social responsiveness, ethical behaviour, concern for welfare and workplace environment. Analysis of descriptive statistics encompassing sample mean, sample standard deviation and sample coefficient of variation revealed that there was significant level of practice of activities used to measure corporate reputation in motor vehicle assembling firms. Analysis of inferential statistics involving simple linear regression analysis found out that corporate reputation positively affects performance of motor vehicle assemblers. Consequently, the conclusion of the study is that corporate culture has positively contribution to performance of motor vehicle assemblers in Nairobi City County, Kenya. It's therefore imperative for human resource managers to formulate clear and inclusive welfare program for stakeholders of the motor vehicle assembling firms. Practices that promote fairness, equality, diversity and dignity in the workplace should be strengthened at all level of the firms in order to project a good image in the market place.

\section{Suggestions for Further Research}

The study was delimited to corporate reputation and performance of motor vehicle assemblers in Nairobi City County. It is therefore necessary for future researcher to consider replicating this study in other industries and sectors with a view to validating the inferences made in this study. It has also been noted that there is significant part of variation of firm performance that could not be explained on the basis of corporate reputation raising a case for the need to investigate other factors that may as well be responsible for performance of motor vehicle assemblers. Finally, future research may need to consider investigating the influence of mediating variables on the relationship between corporate reputation and firm performance.

\section{References}

[1] Barney, J. B. (2002). Gaining and Sustaining Competitive Advantage ( $2^{\text {nd }}$ ed.). Prentice Hall: New Jersey, USA.

[2] Bivens, J. (2003). Updated Employment Multipliers for the US Economy. Working Paper. Economic Policy Institute: Washington, DC, USA.

[3] Black, A., Makundi, B. \& McLennan, T. (2017). Africa's Automotive Industry Potential and Challenges. Working Paper Series, 282, African Development Bank Group.

[4] Bhorat, H. \& Rooney, C. (2017). State of Manufacturing in
South Africa. DPRU Working Paper. MerSETA: Cape Town, South Africa.

[5] Celliers, J. (2017). Made in Africa: Manufacturing and the Fourth Industrial Revolution. Institute for Security Studies, Africa in the World Report, 8.

[6] Covey, S. \& Collins, J.(2004). The 7 Habits of Highly Effective People: Powerful Lessons in Personal Change. Free Press: USA.

[7] Creswell, J. W. (2009). Research Design: Qualitative and Mixed Methods Approaches. SAGE: London, UK.

[8] Denison, D. R, Haaland, R. \& Goelzer, S. P. (2003). Corporate Culture and Organizational Effectiveness: Is there a Similar Pattern around the World? Advances in Global Leadership, 3: 205-227

[9] Fauzul, F. \& Tanaka, Y. (2010). Entrepreneurial Orientation and Business Performance of Small and Medium Scale Enterprises of Hambantota District Sri Lanka. Asian Social Science, 6 (3).

[10] Field, A. (2009). Discovering Statistics using SPSS (2 ${ }^{\text {nd }}$ ed.). Sage: London, UK.

[11] Grant, R. M. (1996). Toward a Knowledge-Based Theory of the Firm. Strategic Management Journal, 17, 109-122.

[12] Hall, E. H. \& Lee, J. (2014). The Impact of Firm Reputation on Performance using Financial Indicators. International Business Research; 7 (12), 1-13.

[13] Jones, G. R. \& Hill, C. L. (2009). Strategic Management: An Integrated Approach. Houghton Mifflin: Boston, USA.

[14] Kaplan, R. S. \& Norton, D. P. (2007). Using the Balanced Scorecard as a Strategic Management System. Harvard Business Review, July-August, 150-161.

[15] KAM (2017). Policy and Sustainability Report. Retrieved 2018, June 18 from www.kam.go.ke.

[16] Kinyua, G. M., Muathe S. M. A., \& Kilika J. M. (2015). Influence of Knowledge Transfer and Knowledge Application on Performance of Commercial Banks in Kenya. Journal of Emerging Issues in Economics, Finance and Banking. 4 (2), 1648-1660.

[17] KNBS (2016). Economic Survey. Government Printers: Nairobi, Kenya.

[18] KNBS (2013). Economic Survey. Government Printers: Nairobi, Kenya.

[19] Kothari, C. R. (2004). Research Methodology-Methods and Techniques. New Age International Publishers: New Delhi, India.

[20] Kumar, R. (2010). Research Methodology: A Step-by-Step Guide for Beginners (3 ${ }^{\text {rd }}$ ed.). SAGE Publication, Inc: London, UK.

[21] Li, Chen and Ma (2016). Corporate Reputation and Performance: A Legitimacy Perspective. Entrepreneurial Business and Economics Review, 3, 181-193.

[22] Lithaa, N. J., Ngugi, K. \& Njagi, L.(2014). Influence of Regulation Practices on Growth of Second Hand Motor Vehicle Dealers in Dagoretti District, Nairobi County, Kenya. European Journal of Business Management, 2 (1), 179-184. 
[23] Madhani, P. M. (2010). Resource Based View (RBV) of Competitive Advantage: An Overview. University Press, Hyderabad, India.

[24] Mbaraka, C. F. (2013). Quality Management Paradigm and Performance in Auto Industry in Kenya. Master of Business Administration: University of Nairobi, Kenya.

[25] MGI (2012). The Archipelago Economy: Unleashing Indonesian Potential. Mckinsey \& Company: USA.

[26] Mugenda, A. \& Mugenda, O. (2003). Readings in Research Methods: Quantitative and Qualititative Approaches. African Centre for Technology Studies Nairobi, Kenya.

[27] Munywoki, H. (2016). Factors Affecting the Sale of New Vehicles in the Motor Vehicle Industry: A Case Study of Simba Corporation Limited, Nairobi. Research Project, Management University of Africa.
[28] Ogolla, N. O. (2013). Operations Strategy and Performance among Motor Vehicle Assemblers in Kenya. Master of Business Administration: University of Nairobi, Kenya.

[29] Otunga, S. I. (2010). Corporate Reputation and Financial Performance of Companies Listed in the Nairobi Stock Exchange. Master of Business Administration: University of Nairobi, Kenya.

[30] Penrose, E. T. (1959). The Theory of the Growth of the Firm. Oxford University Press: New York, USA.

[31] Stafford, D \& Miles, L. (2013). Integrating Cultures after a Merger. Bain \& Company: Washington, DC, USA.

[32] Wernefelt. B. (1984). A Resource Based View of the Firm. Strategic Management Journal, 5 (2): 1171-180.

[33] Yamane, T. (1967). Statistics: An Introductory Analysis (2 $2^{\text {nd }}$ ed.). Harper and Row: New York, USA. 